\title{
À la croisée des chemins : les officiers de marine russes entre Révolution et contre-révolution
}

Traduit du russe par Éric Aunoble (2021)

\author{
Kirill NAZARENKO \\ Professeur \\ Institut d'Histoire \\ Université d'Etat de Saint-Pétersbourg (RU) \\ k.nazarenko@spbu.ru
}

\section{Doi :10.5077/journals/connexe.2021.e319}

\begin{abstract}
Résumé
Le destin des officiers russes pendant la Guerre civile est un champ d'étude toujours actif. L'auteur a constitué une base de données des officiers de la Marine, aux fins d'analyse prosopographique. Cette analyse statistique des biographies après 1917 permet de savoir précisément quel pourcentage d’officiers a rejoint tel camp politique, s'est abstenu de participer à la Guerre civile, a émigré ou est resté en Russie soviétique, quelle proportion a changé de camp, etc. On peut ainsi faire le point sur leurs engagements politiques de façon objective. Même si elle représente un pas en avant par rapport aux approches souvent partielles et partiales qui prévalaient dans l'historiographie, l'étude prosopographique et statistique n'a d'intérêt que si elle permet aussi d'interroger les motivations des acteurs, de détailler les facteurs, idéologiques ou de carrière, qui ont déterminé leurs choix politiques et d'en évaluer l'influence respective.

Pour ce faire, cet article se concentre sur les officiers de marine qui étaient enregistrés à Petrograd en 1918, au moment de la dissolution de l’ancienne marine impériale par décision du nouveau pouvoir bolchevique.
\end{abstract}

Mots-clés : guerre civile, Russie 1917-1921, Marine russe, officiers de marine, histoire militaire.

\begin{abstract}
The fate of Russian officers during the Civil War is still an active field of study. The author has compiled a database of naval officers for prosopographical analysis. This statistical analysis of the biographies after 1917 makes it possible to know precisely what percentage of officers joined which political camp, abstained from participating in the Civil War, emigrated or remained in Soviet Russia, what proportion changed sides, etc. In this way it is possible to take stock of their political commitments in an objective way. Although it represents a step forward compared to the often partial and biased approaches that prevailed in historiography, the prosopographical and statistical study is only of interest if it also allows us to question the motivations of the actors, to detail the factors, ideological or career, that determined their political choices and to evaluate their respective influence.

To this end, this article focuses on the naval officers who were registered in Petrograd in 1918, at the time of the dissolution of the former Imperial Navy by decision of the new Bolshevik power.
\end{abstract}

Keywords: Civil War, Russia 1917-1921, Russian Navy, naval officers, military history. 


\section{Introduction}

Le destin des officiers russes durant la période cruciale qui va de la Première Guerre mondiale à la Guerre civile, puis à l'émigration, en passant par les révolutions de Février et d'Octobre, a toujours intéressé la recherche. Les diverses analyses du corps des officiers dans le premier quart du $\mathrm{XX}^{\mathrm{e}}$ siècle sont pourtant contradictoires et les historiens ont formulé des hypothèses opposées quant à leurs choix politiques lors de ces fractures successives. Certains ont affirmé que la majorité des officiers soutenaient le mouvement blanc (Волков 1993) tandis que d'autres soutenaient qu'ils étaient passés en masse du côté du pouvoir soviétique (Кавтарадзе 1988 ; Березовский 1996). En réalité, qu'ils soient restés en Russie ou aient finalement émigré, les choix qui s'offraient aux officiers formés sous l'Ancien Régime étaient sensiblement plus vastes. Certains avaient pu éviter de prendre part à la Guerre civile tandis que d'autres s'étaient enrôlés auprès des forces armées de nouveaux États nés sur le territoire de l'ex-Empire russe ou s'étaient même engagés auprès d'une puissance étrangère (comme la Grande-Bretagne ou la Roumanie) (Стрельбицкий 2003 ; Никитин 2017). Il reste que les thèses avancées sur tel ou tel aspect de l'activité du corps des officiers semblent surtout relever d'a priori car elles sont fondées sur des exemples isolés, sur quelques mémoires et, parfois, sur des documents administratifs.

En cequi concernel'Armée deterre, la discussion entreV.V. Kaminskij(Каминский 2011) et ses opposants, au premier rang desquels A.V. Ganin (Ганин 2014), a marqué l'historiographie. Les deux auteurs divergeaient sur la quantité d'officiers du corps de l'état-major de l'infanterie ralliés aux rouges et sur leurs motivations. Alors que, d'après Ganin, 40 \% d'entre eux servaient le nouveau pouvoir notamment par conviction, ils étaient plus de $50 \%$ pour Kaminskij, qui soulignait quant à lui le poids des intérêts matériels dans ce choix. Leur échange a fini par prendre un ton aigre (Каминский 2013) et A.V. Ganin a tenté ultérieurement de dresser un bilan provisoire des trajectoires des officiers d'infanterie pendant la Guerre civile (Ганин 2018).

La situation dans la marine n'est pas mieux connue. Les officiers de carrière de la marine qui ont servi dans l'Armée et la Marine rouges ${ }^{1}$ n'ont été que peu étudiés ou alors essentiellement sous l'angle de la répression dont ils ont pu faire l'objet (Ковалев 2006). À propos de ceux qui firent le choix opposé, on dispose d'un essai de « martyrologe » des officiers de marine russes des années 1910-1920 (Волков 2004 ; Лобыцын 2001). Ce travail ne couvre que partiellement ce corps tout en comprenant aussi des personnes qui n'en sont pas issues. De plus, le choix de collecte des données paraît largement subjectif et l’information n'étant guère structurée, cela ne permet

1 De leurs noms complets : Armée rouge ouvrière et paysanne et Marine rouge ouvrière et paysanne (NdT). 
pas d'en tirer des conclusions solides. Enfin, cet annuaire ne recense que des officiers de carrière qui se sont retrouvés dans l'émigration après la Guerre civile.

Toujours en ce qui concerne les officiers du « vieux » corps ayant quitté la Russie, l'intérêt des chercheurs s'est surtout porté sur leur participation aux organisations politiques et sociales de l'émigration russe (Кузнецов 2009 ; Толочко 2012), laissant de côté les possibilités d'une analyse prosopographique complète embrassant toute leur carrière. De plus, en se concentrant sur les «vieux » officiers de carrière, les historiens N.A. Kuznecov et A.V. Toločko ont laissé dans l'ombre les officiers de réserve et les officiers du temps de guerre ${ }^{2}$.

Ces officiers de réserve et du temps de guerre, qui représentaient tout de même 35,5 \% de l'encadrement de la marine à la fin de 1917, restent en fait peu étudiés. Il est vrai que cette étude est compliquée par le fait qu'une bonne part des officiers de réserve étaient estoniens ou lettons et s'étaient installés dans leur pays d'origine après la Guerre civile. Aujourd'hui, un fichier complet des gradés de l'armée et de la marine estoniennes est accessible sur le site internet du Musée Militaire Laidonari (Eesti Sõjamuuseum). Il permet de mieux connaître les états de service des anciens officiers russes dans les forces armées de l'Estonie indépendante. La publication d'un certain nombre d'annuaires permet également d'étudier le rôle de ceux qui sont finalement passés sous les drapeaux polonais et lituanien (Kadry Morskie Rzeczypospolitej 2011 ; Melderis 2016).

Nombre d'officiers de réserve et du temps de guerre ont pu aisément retourner à la vie civile, et ainsi « se perdre » dans la population de Russie soviétique, d'autant qu'ils avaient un niveau d'étude permettant une réorientation professionnelle ${ }^{3}$. Grâce au développement de la généalogie et de l'histoire locale en Russie contemporaine, mais aussi grâce à l'analyse méthodique d'informations mises à disposition sur Internet, des informations biographiques nombreuses mais disparates ont été produites sur les Soviétiques des années 1920-1940 et sur les participants de la "Grande Guerre patriotique ». Parmi eux, on compte d'anciens officiers de marine et, s'il est chronophage de les retrouver dans ces sources, ce travail est utile ${ }^{4}$.

La nécessité se faisant sentir d'une approche globale, j’ai dirigé en 2015-2017

2 Les officiers du temps de guerre sont ceux qui : 1) avaient reçu une formation maritime civile, avaient servi plusieurs mois en tant que marin et passé l'examen de lieutenant de vaisseau des armes ou des services (ou, en 1917, l'examen d'enseigne de vaisseau en temps de guerre) ; 2) ayant terminé l'enseignement secondaire général, avaient fait l'école des lieutenants de vaisseau de l'amirauté (ou, en 1917, l'école des enseignes de vaisseau de la marine côtière en temps de guerre).

3 Ils avaient pour la plupart reçu une éducation secondaire complète et souvent supérieure ou, à tout le moins, une formation maritime.

4 Voici les plus importants projets de ce genre : Подвиг народа. 1941-1945. [Эл. peсурс] ; Память народа. 19411945. [Эл. ресурс] ; Мемориал. [Эл. ресурс] ; Памяти героев Великой войны. 1914-1918. [Эл. ресурс] ; Офицеры русской императорской армии. [Эл. ресурс] ; Возвращенные имена : Книга памяти России. [Эл. peсурс]; Открытый спис+/- [Эл. ресурс] ; База данных “Жертвы политического террора в СССР”. [Эл. ресурс]. 
le projet intitulé «Le corps des officiers de marine russe de la Première Guerre mondiale et de la Guerre civile : étude prosopographique exhaustive ». Ce projet a été à l'origine de plusieurs publications (Назаренко 2017 ; Назаренко 2018) qui détaillent les caractéristiques les plus importantes du corps des officiers de marine pendant la Première Guerre mondiale. Il est apparu que la Guerre civile méritait une étude spécifique non seulement quant aux choix politiques des «vieux » officiers, mais aussi sur d'autres aspects de leur carrière : la longévité dans le grade, la rapidité d'avancement, le niveau d'étude selon les catégories, etc. Il en a résulté une base de données accessible à tous (Офицеры флота 2017) qui est un puissant instrument d'analyse prosopographique. Elle est complétée dans le cadre d'un nouveau projet en cours de réalisation qui porte sur l'analyse statistique des biographies d'ex-officiers de marine après $1917^{5}$.

Cette analyse statistique des biographies permet de savoir précisément quel pourcentage d'officiers a rejoint tel camp politique, s'est abstenu de participer à la Guerre civile, a émigré ou est resté en Russie soviétique, quelle proportion a changé de camp, etc. On peut ainsi faire le point sur leurs engagements politiques de façon objective. Même si elle représente un pas en avant par rapport aux approches partielles et partiales qui prévalaient dans l'historiographie, l'étude prosopographique et statistique n'a d'intérêt que si elle permet de dépasser le constat pour interroger les motivations des acteurs, détailler les facteurs qui ont déterminé leurs choix politiques et en évaluer l'influence respective. Fondé sur la base de données que nous avons constituée, cet article se limitera à l'étude des officiers de marine qui étaient enregistrés à Petrograd en 1918, au moment de la dissolution de l'ancienne marine impériale par décision du nouveau pouvoir bolchevique.

\section{L' « Affaire Ščastnyj » et le moment 1918}

Pour comprendre à quel point 1918 fut une année charnière dans le destin des officiers, il faut d'abord souligner l'événement crucial que fut « la Campagne de Glace de la flotte de la Baltique ». De mars à mai 1918, presque tous les bâtiments de combat et la majorité des navires auxiliaires ont été transférés de la base navale d'Helsingfors (aujourd'hui Helsinki en Finlande) vers Kronstadt et Petrograd (aujourd'hui Saint-Pétersbourg en Russie), et ce malgré les glaces prenant le Golfe de Finlande. Les spécialistes pensaient un tel projet irréalisable avant qu'il ne fût accompli. Ce mouvement permit d'éviter que les Allemands et les Finlandais blancs ne mettent la main sur ces navires après la prise d'Helsingfors le 11 avril 1918. Durant

5 Проект Российского фонда фундаментальных исследований №19-09-00081 А “Старое” русское морское офицерство после 1917 г. : Сплошное просопографическое исследование. RFBR project № 19-09-00081 A "Old” Russian naval officer corps after 1917: complete prosopographic survey. 
cette Campagne de Glace, la flotte était commandée par le capitaine de vaisseau ${ }^{6}$ Aleksej Ščastnyj (1882-1918), qu'on qualifie encore parfois improprement d'amiral. Un mois après ce succès, Ščastnyj était déféré au tribunal où il subit un procès public et fut finalement fusillé pour agitation contre-révolutionnaire et participation à un complot. Ces événements connurent une grande résonance à l'époque et s'imprimèrent dans la mémoire historique. Aujourd'hui, le grand public russe ne connaît guère que Ščastnyj et Kol'čak comme marins ayant participé à la Guerre civile, et l'historiographie a renforcé l'image d'un Ščastnyj comme victime innocente des bolcheviks et, en l'espèce, de Trotski (Шошков 2001 ; Рабинович 2001). Nous avons consacré une monographie à la biographie politique de Ščastnyj, ce qui nous autorise à conclure qu'il fut bien impliqué dans un complot antibolchevique, mais que la faiblesse et l'absence de professionnalisme des services spéciaux soviétiques ne permirent pas d'en réunir les preuves. De plus, Trotski commit un certain nombre d'erreurs graves à des fins de propagande tandis que Ščastnyj de son côté fit tout pour entrer dans l'histoire comme un héros. En conséquence, aux yeux du grand public et d'une bonne partie des officiers de marine, Ščastnyj perdit un duel idéologique et le paya de sa vie (Назаренко 2020a).

La mort de Ščastnyj influença profondément l'attitude des officiers de marine visà-vis des bolcheviks, mais pas de façon uniforme. Elle en poussa certains à lutter contre les bolcheviks, tandis que d'autres se soumirent au contraire à leur pouvoir par peur. Enfin, il s'en trouva un bon nombre pour voir dans cette condamnation à mort une preuve d'autorité des nouveaux dirigeants de la Russie qui contrastait positivement avec l'attitude du gouvernement provisoire et singulièrement avec celle d'Aleksandr Kerenskij. Représentants d'un « pouvoir fort » au milieu d'un " océan de chaos », les bolcheviks pouvaient ainsi attirer des officiers.

\section{Un choix politique multifactoriel}

Si on envisage les facteurs concrets des choix politiques des officiers recensés à Petrograd en 1918, il faut d'abord souligner les réseaux de relations qui structuraient ce groupe social. Le corps des officiers de marine russes était en effet divisé en différents groupes relativement étanches : les officiers des armes ${ }^{7}$, les ingénieurs mécaniciens, les officiers en l'amirauté, les officiers de réserve, etc. Il serait trop long de détailler toutes les nuances qui réglaient la formation de ces sous-groupes et les relations qu'ils entretenaient entre eux, mais le lecteur trouvera des informations dans une étude spécifique (Назаренко 2018).

6 Capitaine de premier rang dans la nomenclature de la marine russe (NdT).

7 Traduction de stroevye oficery. En français contemporain, on distingue parmi les officiers de marine : les officiers des armes et les officiers des services (notamment les ingénieurs-mécaniciens et les ingénieurs des travaux maritimes) (C.I.N. 2012, 290) (NdT).

CONNEXE 7| 2021 - La Guerre civile après 1917 : les échelles d'un conflit et sa représentation 
L'important est de savoir que les écoles de formation étaient le creuset de la sociabilité des officiers. C'est particulièrement vrai pour les officiers des armes dont 90 \% étaient passés par le Corps des cadets de la marine avant 1914 et provenaient du même milieu social. En effet, jusqu'en 1907, il y avait des barrières sociales rendant les conditions d'accès à ce corps extrêmement restrictives : il fallait non seulement appartenir à la noblesse héréditaire, mais aussi être soi-même de préférencele fils d'un officier des armes. À partir de 1907, en plus des descendants de la noblesse héréditaire, on admit les enfants d'officiers, de fonctionnaires (de rang moyen et élevé), de prêtres et de gens ayant reçu une éducation supérieure. En tout, ces catégories représentaient $2 \%$ de la population russe... Le candidat devait aussi être de confession chrétienne, mais pas forcément orthodoxe. Un musulman pouvait toutefois accéder au Corps des cadets de la marine sur autorisation personnelle du tsar. Par contre, les juifs, les bouddhistes et les païens (dans la terminologie officielle de l'époque) n'étaient pas admis. On peut mesurer la force du lien social qui en résultait en relevant les mentions d'anciens officiers dans les publications spécialisées de l'émigration, le plus souvent à l'occasion de décès de tel ou tel officier émigré : presque tous les diplômés du Corps des cadets de la marine ayant émigré y sont mentionnés.

Les officiers qui avaient suivi les Cours spéciaux de Garde-marine (créés en 1913) étaient plus faiblement liés entre eux, ce qui peut s'expliquer par le moindre temps d'étude (trois ans contre six au Corps des cadets de la marine). Seuls $65 \%$ des Gardes-marine sont ainsi mentionnés dans les publications corporatives, alors même que les critères sociaux d'admission étaient les mêmes que pour le Corps des cadets. Quant aux diplômés de l'Institut des ingénieurs de la marine, on ne retrouve que $60 \%$ d'entre eux dans les publications. Plus ténues encore étaient les connexions des officiers diplômés des Cours des Gardes-marine de la flotte, créés en 1916 : le cursus ne durait qu'un an, les étudiants avaient déjà fait des études supérieures et ils n'étaient soumis à aucun critère de sélection sociale. Or, ils sont quasiment absents des nécrologies publiées dans l'émigration et ne sont pas cités dans les mémoires (Назаренко 2020b).

On comprend donc qu'un officier issu des milieux privilégiés de l'Empire et ayant bénéficié d'une formation longue au sein du prestigieux Corps des cadets ferait plus facilement le choix de quitter la Russie soviétique que d'autres officiers, de plus basse extraction et moins intégrés à la caste militaire.

On pourrait penser que les convictions politiques seraient un facteur déterminant de leurs prises de position. Or, avant la Révolution, les officiers de l'Armée et de la Marine étaient formellement « en dehors de la politique » et ne disposaient pas, par exemple, du droit de vote aux élections de la Douma d'État. La plupart d'entre eux ne s'intéressaient d'ailleurs pas à la lutte de partis dont ils ne se sentaient pas proches, 
s'estimant liés avant tout à la monarchie. De plus, les partis étaient regardés comme un facteur de division nuisible en soi dans la mesure où leur simple existence contredisait l'idée d'unité de l'État et des forces armées, idée qui était pour eux l'incarnation de la plus haute valeur morale.

L’expression claire d'opinions politiques était de plus bridée par principe dans les rangs des forces armées, ce qui représentait un frein supplémentaire. Ainsi, seules quelques individualités se risquèrent à faire des déclarations antibolcheviques fin 1917 et début 1918 (Мажара 2019). De même, les cas d’adhésion au Parti Communiste (bolchevique) Russe [PC(b)R] sont rarissimes. Dans les années 1920, sur un millier d' « anciens officiers » qui servaient dans la Marine rouge, il n'y en avait, selon nos relevés, pas plus de 30 qui étaient membres du PC(b) soviétique. De plus, ces derniers n'étaient majoritairement pas des officiers de carrière, mais des officiers de réserve ou des officiers du temps de guerre (Офицеры флота 2017).

Cette retenue ne signifie pourtant pas que les officiers n'aient pas eu de position politique. Le célèbre orientaliste russe Georgij Mirskij (1926-2016) avait émis l'idée selon laquelle les officiers de carrière « apolitiques » ont un système de représentations qui constitue en fait l'idéologie commune des militaires professionnels (Мирский 1976). Ces idées qui se forment dans les forces armées et «fonctionnent » dans ce milieu spécifique peuvent être résumées ainsi :

1) le patriotisme, valeur suprême, implique que tout pouvoir qui défend les frontières et le prestige de l'État peut recevoir le soutien des officiers de carrière ;

2) la conviction en l'inefficacité totale des procédures démocratiques ;

3) la discipline et l'ordre comme valeurs en soi et conditions nécessaires de tout processus positif ;

4) l'extension du paternalisme ressenti vis-à-vis des soldats à toute la société, au peuple, à l'État ;

5) le refus de considérer la richesse et la réussite dans les affaires comme unique critère de succès dans la vie. Cet ensemble d'idées peut bien entendu être détaillé et élargi, mais nous le présentons sous cette forme concentrée au maximum pour illustrer son influence sur les choix politiques des officiers de marine à Petrograd en 1918.

Soulignons que ce corpus de valeurs est caractéristique des militaires de carrière, et non des officiers de réserve ou du temps de guerre qui se considéraient comme intégrés au corps civique et à leurs groupes socio-professionnels d'origine et pas à l'Armée ou à la Marine. Cependant, ces valeurs pouvaient quand même attirer ceux des officiers du temps de guerre qui rêvaient de poursuivre une carrière militaire après le conflit. Ces valeurs étaient conciliables avec plusieurs tendances du spectre politique civil. Ainsi l'enseigne de vaisseau ${ }^{8}$ Georgij Lisanevič, qui a dirigé la mutinerie malheureuse de la division de torpilleurs de la flotte de la Baltique contre les bolcheviks

8 Mitchman dans la nomenclature de la marine russe (NdT).

CONNEXE 7 | 2021 - La Guerre civile après 1917 : les échelles d'un conflit et sa représentation 
à Petrograd en mai-juin 1918, était un monarchiste d'après les mémoires célèbres du capitaine de frégate ${ }^{9}$ Garal'd Graf (Граф 1997, 351). Par contre, Vladimir Ignat'ev, l'un des dirigeants du parti socialiste-populaire, activiste antibolchevique clandestin à Petrograd le considérait "plutôt comme un bolchevik que comme un socialiste droitier » (Игнатьев 1922, 19). On peut donc penser qu'un officier qui partageait la vision du monde décrite plus haut ne serait ni libéral, ni anarchiste, mais pouvait rejoindre les rangs des partisans d'un pouvoir fort qu'ils fussent de droite ou de gauche.

Un troisième facteur important dans les choix politiques était l'incompréhension des objectifs politiques réels tant des bolcheviks que de leurs adversaires. Dans la mesure où les officiers avaient peu d'expérience politique, ils avaient du mal à appréhender les slogans mis en avant par les partis et, parfois, ils ne les comprenaient pas du tout. En particulier, des slogans bolcheviques clés, tels que "la terre aux paysans » et « la paix aux peuples », étaient reçus avec indifférence pour le premier et avec hostilité pour le second. Les "vieux » officiers comprenaient la révolution comme la victoire du chaos sur l'ordre et y voyaient d'abord l'assurance de la défaite militaire. C'est pourquoi ces officiers pouvaient exagérer le préjudice que représentait le traité de Brest-Litovsk pour la Russie et être persuadés qu’il transformerait la Russie en colonie allemande pour des décennies. Cette perception faussée des enjeux politiques poussait les officiers vers des positions antibolcheviques.

Néanmoins, les officiers n'étaient pas attirés par les socialistes droitiers qu’ils associaient au régime d’Aleksandr Kerenskij, lequel s'était totalement discrédité à leurs yeux par sa faiblesse. Il faut noter aussi que les opposants aux bolcheviks confondaient ces derniers avec les anarchistes en essayant de présenter les bolcheviks comme les ennemis de toute forme d'État, ce qui provoquait immanquablement un rejet chez les officiers. De ce point de vue, les mesures « étatiques » autoritaires et vigoureuses prises par les bolcheviks pouvaient « réhabiliter » ces derniers aux yeux des officiers. Ainsi la volonté bolchevique de rétablir une discipline rigoureuse à l'Armée et dans la Marine jouait ici en leur faveur.

En quatrième lieu, il faut compter avec les ambitions politiques personnelles des officiers de marine, lesquelles pouvaient s'exprimer sous deux formes. Certains officiers manifestaient ces ambitions en participant directement à la lutte politique et en essayant donc de devenir par eux-mêmes des dirigeants politiques pendant la Guerre civile. Au-delà des exemples célèbres de l'amiral Kol'čak et du capitaine de vaisseau Ščastnyj, il en existe d'autres moins connus. Mis à part l'enseigne de vaisseau Lisanevič, déjà mentionné, citons : le capitaine de frégate Georgij Čaplin, dirigeant de la mutinerie antibolchevique d'Arkhangelsk en août 1918 ; l'enseigne de vaisseau

9 Capitaine de $2^{e}$ rang dans la nomenclature de la marine russe (NdT).

CONNEXE 7 | 2021 - La Guerre civile après 1917 : les échelles d'un conflit et sa représentation 
Vasilij Lemlejn, un des leaders de la Dictature de Caspienne centrale qui avait chassé les bolcheviks de Bakou en août 1918 et avait appelé les troupes britanniques à l'aide contre l'offensive ottomane ; enfin, le capitaine de corvette ${ }^{10}$ Georgij Veselyj, éminence grise du soviet de Mourmansk qui a joué un rôle décisif pour retourner cette institution contre les bolcheviks (le soviet fera appel à l'intervention britannique en mars-juin 1918).

En défendant les intérêts de la marine au sein del'appareil d'État, certains « vieux » officiers qui étaient passés formellement du côté des soviets manifestaient aussi leurs ambitions. En 1918-1922, les contre-amiraux de l'ancienne marine Vasilij Al'tfater et Aleksandr Nëmitc, ainsi que le capitaine de vaisseau Evgenij Berens occupaient des postes élevés dans la Marine rouge.

En 1921-1922, on observa même des velléités d' « impérialisme rouge » chez les « vieux » officiers au service des soviets. Ils insistaient sur la nécessité de construire une marine puissante pour soutenir des tentatives révolutionnaires dans des pays lointains. Luttant ainsi pour obtenir le financement de la remise en état de la marine qui était leur principale préoccupation, ils s'opposaient au commissaire du peuple à la Guerre. En effet, Léon Trotski comptait, quant à lui, sur la révolution permanente (Назаренко 2019, 359-416). On touche ainsi à la question plus large de l'influence des organes supérieurs de commandement militaire sur l'élaboration de la politique intérieure et extérieure de l'État, non seulement dans les années 1920-1930, mais tout au long du $\mathrm{XX}^{\mathrm{e}}$ siècle. Il est indéniable que les officiers de marine avaient l'envie et les capacités intellectuelles pour exercer une telle influence. Par contre, le succès de leurs entreprises dépendait beaucoup de la situation du moment et des personnalités politiques civiles sur lesquels ils entendaient s'appuyer.

\section{Des enjeux internationaux}

Les bruits quant aux contacts entre les bolcheviks et le gouvernement allemand constituent un cinquième facteur d'importance. Ces rumeurs, qui ont été étudiées récemment par P. Ju. Mažara (Мажара 2019), ont été largement relayées par les journaux, car il faut rappeler que jusqu'à l'automne 1918, beaucoup de publications non-bolcheviques et même antibolcheviques ont continué de paraître. Parmi les rumeurs qui ont ainsi eu une grande résonance, il y avait celle concernant l'existence de clauses secrètes au traité de paix de Brest-Litovsk, lesquelles auraient stipulé le transfert de la flotte de la Baltique et de celle de la mer Noire aux Allemands. On prétendait même que le gouvernement soviétique était sous le contrôle total des Allemands. Pavel Dybenko, un des leaders des marins révolutionnaires, s'en était même fait l'écho lors de son procès public à Moscou en mai 1918 ( « Дело Дыбенко ».

10 Lieutenant sénior dans la nomenclature de la marine russe (NdT).

CONNEXE 7 | 2021 - La Guerre civile après 1917 : les échelles d'un conflit et sa représentation 
1918. Заря России, № 24. 19 мая. С. 3.). Ces rumeurs avaient été renforcées par les «documents Sisson », du nom du représentant personnel du président étatsunien Woodrow Wilson à Petrograd. Il avait fait l'acquisition d'une grosse liasse de documents et il en soutint ardemment l'authenticité quand elle fut mise en doute. Or, comme l'a définitivement montré V.I. Starcev, les « documents Sisson » étaient un faux artistiquement fabriqué par Ferdynand Ossendowski, un homme de lettres pétersbourgeois d'origine polonaise (Старцев 2001). Il contrefit ainsi 200 documents concourant à prouver la sujétion des bolcheviks aux Allemands.

On sait aujourd'hui que ces documents ont connu en 1918 une diffusion en Russie beaucoup plus importante qu'on ne le croyait. Nous avons même pu établir que certaines des pièces relatives à la marine circulaient de main en main, non seulement entre de "vieux » officiers mais même parmi les commissaires. Les faux étaient copiés, la presse les reprenait, et tout cela accroissait leur circulation (Назаренко 2020a, 373-386).

Soulignons que l'effondrement de l'Allemagne impériale en novembre 1918, l'armistice à l'ouest et la Révolution allemande conduisirent les bolcheviks à rompre le traité de Brest-Litovsk et à tenter de reprendre le contrôle de la côte de la Baltique, de la Biélorussie, de l'Ukraine et du Caucase qui avaient été perdus au profit des Allemands, des Autrichiens et des Ottomans. Cette reconquête fut totalement soutenue par une bonne partie des officiers et contribua à rehausser la cote des bolcheviks ainsi reconsidérés comme des " hommes d'État ». En conséquence, l'influence des « documents Sisson » s'affaiblit à partir de novembre 1918 même si elle ne disparût pas entièrement.

L'influence des services britanniques sur les « vieux » officiers de marine est un sixième facteur. Il suffit de dire que tout le personnel de l'espionnage de la marine russe au premier rang duquel son chef, le capitaine de frégate Viktor Vinogradov, avait été recruté par les Britanniques et agissait sous les ordres du commander Francis Cromie, attaché militaire à l'ambassade du Royaume-Uni et chef du réseau d'espionnage à Petrograd (Зданович 2003, 99-103 ; Зданович 2017, 101-115). L'activité de Cromie était favorisée par l'aura dont il jouissait depuis qu'il avait commandé la flottille des sous-marins de la Baltique basée dans des ports russes en 1915-1917. De plus, les officiers de marine russes del'époque nourrissaient un profond respect pour la marine britannique et ses officiers réputés gentlemen. Les objectifs des services de renseignement britanniques avaient toutefois évolué rapidement. En février-mars 1918, ils essayaient d'organiser la résistance contre les Allemands, mais, à partir d'avril, ils étaient passés à la lutte pour le renversement du gouvernement soviétique. Ils attendaient en effet d'un changement de gouvernement qu'il ramène la Russie dans la guerre contre l'Allemagne. Les Britanniques préparaient également 
une intervention de l'Entente en Russie. Les « vieux » officiers entraînés dans cette activité clandestine pouvaient ne pas être conscients de cette inflexion et restaient persuadés de continuer d'agir au premier chef contre les Allemands (Назаренко 2020a, 198-210).

La volonté de ne pas participer activement à une guerre civile « fratricide » est un septième facteur de choix, mais ce « pacifisme » n'était pas qu'une question d'idéaux. Sergej Minakov, un spécialiste renommé du corps des officiers de l’Armée russe a expliqué que, pendant la Guerre civile, les unités militaires les plus efficaces avaient été constituées par affinité, comme des milices, autour d'un chef charismatique chanceux, doué militairement et capable de résoudre les problèmes de ravitaillement au milieu du chaos. L'origine et le statut antérieur d'un tel «chef » importaient peu et, le plus souvent, il s'agissait d'un homme jeune et énergique. Napoléon en est un exemple classique et, concernant la Guerre civile en Russie, on peut citer notamment le cavalier rouge Semen Budënnyj, l'ataman blanc Grigorij Semenov, le paysan anarchiste Nestor Makhno... Dans la marine, ce sont donc surtout des flottilles fluviales qui furent constituées sur une base affinitaire, avec à leur tête des commandants jeunes, de l'âge des officiers subalternes de la "vieille » marine (Павленко 2019, 174-177). Les grandes formations militaires de la marine, comme les flottes de la Baltique et de la mer Noire, ont par contre continué à fonctionner de façon traditionnelle, les « vieux » officiers gardant leur place d'avant la Révolution dans la hiérarchie. D'anciens amiraux commandaient ces flottes et la structure des cadres de commandement n'avait guère été modifiée. En conséquence, les officiers qui ne voulaient pas participer à la Guerre civile avaient en fait plusieurs motivations : 1) le dégoût pour une guerre «fratricide»;2) la préférence pour le combat contre un ennemi extérieur (qui trouvera à s'assouvir en particulier sur la Baltique face à l'Intervention britannique en 1919) ; 3) l'envie de conserver son affectation et son statut ; 4) l'inappétence au risque de diriger des combats sur les fleuves ou les côtes, sans ravitaillement, sans organisation et sans bâtiments idoines.

\section{Les enjeux de nationalité}

Enfin, les préférences nationales et ethniques ont également joué leur rôle. On comptait près de $10 \%$ d'Allemands de la Baltique et de Polonais parmi les officiers de carrière de la " vieille » marine. Quant aux Estoniens et aux Lettons, ils étaient nombreux parmi les officiers de réserve et du temps de guerre. Si les uns et les autres occupaient diverses fonctions, il apparaît que les Allemands de la Baltique représentaient un groupe privilégié vis-à-vis des autres, y compris par rapport aux Russes ethniques : cela apparait clairement quand on se livre à une étude statistique des carrières (Копелев 2000). 
Alors que l'Empire russe s'effondrait, un nouveau choix apparut : entrer dans les forces armées d'une république nationale indépendante. D’après nos calculs, après 1920, on retrouvait 234 ex-officiers de la marine russe sous les drapeaux polonais, près de 100 au service de l'Estonie et de la Lettonie et moins de 10 respectivement dans les forces armées finlandaises et roumaines (Kadry Morskie Rzeczypospolitej 2011). Il faut évidemment faire la différence entre un officier resté sur le territoire finlandais après le retrait des troupes russes et devenu émigré (il y en avait bien plus de dix !) et ceux qui prirent effectivement du service auprès du nouvel État. Alors qu'on comptait 8325 officiers de marine en Russie au $1^{\text {er }}$ janvier 1918 , seuls $5 \%$ d'entre eux s'engagèrent pour un nouvel État. Néanmoins, en Estonie et en Lettonie, les ex-officiers russes constituaient l'écrasante majorité des officiers de la nouvelle marine. En Pologne, ils représentaient 70 \% du corps, les autres provenant de la marine austro-hongroise et, marginalement, de la Kriegsmarine.

Presqu'un millier d'anciens officiers de la flotte de la mer Noire sont quant à eux passés en juillet-août 1918 dans la marine ukrainienne. Il ne faut pourtant pas se tromper sur cet engagement massif au service de l'État ukrainien de l'hetman Pavlo Skoropadsky à l'été 1918. Il s'agissait essentiellement pour les officiers de trouver un refuge pendant une des étapes de la Guerre civile et de nourrir leur famille. Après l'effondrement de l'hetmanat ukrainien, presque tous passèrent dans les rangs des blancs et on ne trouvera que dix «vieux » officiers de marine russes au service de la République populaire d’Ukraine [UNR] (Офицеры флота 2017). Cet exemple suggère que l'engagement auprès d'autres États pourrait aussi avoir été à l'origine un choix conjoncturel devenu définitif vu la suite des événements.

\section{Un bilan}

Il est évident que le critère objectif pour attester le choix politique d'un officier est son passage au service de telle ou telle force politique. Grâce aux données préliminaires tirées de l'analyse statistique des biographies des officiers de la « vieille » marine après 1917 , nous pouvons faire quelques observations. 


\begin{tabular}{|c|c|c|c|c|}
\hline \multirow[t]{2}{*}{$\begin{array}{l}\text { Tableau } 1 . \text { Nombre d'officiers de la marine } \\
\text { russe par catégorie, au } 1 / 01 / 1918^{11}\end{array}$} & \multicolumn{2}{|c|}{ Officiers de carrière } & \multicolumn{2}{|c|}{$\begin{array}{l}\text { Officiers de réserve et } \\
\text { du temps de guerre }\end{array}$} \\
\hline & Nombre & Pourcentage & Nombre & Pourcentage \\
\hline Généraux et amiraux des armes & 98 & $1,2 \%$ & / & / \\
\hline Officiers des armes à l'état-major & 603 & $7,2 \%$ & / & / \\
\hline Officiers supérieurs des armes & 2070 & $24,9 \%$ & 1754 & $21,1 \%$ \\
\hline Ingénieurs mécaniciens (officiers et généraux) & 942 & $11,3 \%$ & 454 & $5,5 \%$ \\
\hline Officiers et généraux en l'amirauté & 1271 & $15,3 \%$ & 288 & $3,5 \%$ \\
\hline Aspirants-spécialistes (anciennement conducteurs) & / & I & 461 & $5,5 \%$ \\
\hline Autres & 384 & $4,6 \%$ & I & I \\
\hline Total & 5368 & $64,5 \%$ & 2957 & $35,5 \%$ \\
\hline
\end{tabular}

\begin{tabular}{l} 
Tableau 2. Affectation des officiers de la marine russe par \\
\cline { 2 - 3 } flotte et flottille, fin $\mathbf{1 9 1 7}$
\end{tabular}

Nous nous concentrerons sur le cas de la flotte de la Baltique et de la Flottille de l'Océan glacial Arctique qui correspondent pour l'essentiel aux officiers enregistrés à Petrograd. Il est toutefois intéressant de noter qu'en été et en automne 1918, la plupart des officiers de la flotte de la mer Noire étaient officiellement au service de l'État Ukrainien et la question de leur choix politique ne se posait pas de façon aussi aiguë qu'aux officiers de la flotte de la Baltique ${ }^{12}$.

Les officiers de réserve dela flotte de la Baltique auraient dû être démobilisés en juin 1918, ce qui impliquait le licenciement d'environ 35 \% des officiers, alors qu'environ 3000 officiers de carrière devaient rester en service. En réalité, même si la plupart des officiers de réserve et du temps de guerre ont certainement été démobilisés, la mesure n'a pas touché tout le monde. Dès septembre 1918, une nouvelle mobilisation des officiers a commencé, mais elle n'a pas permis de reconstituer la marine car la

11 Российский государственный архив Военно-Морского Флота (РГА ВМФ), Ф. Р-187, оп. 1, д. 509, л. 4-5 ; Ф. Р-5, оп. 1, д. 82, л. 22-29 (об.).

12 Quant aux autres formations de la marine, elles étaient trop petites pour autoriser une analyse quantitative. 
priorité était alors donnée au renforcement de l'Armée rouge. En particulier, cela a conduit au fait qu'une partie des officiers de réserve de la marine a été appelée dans l'Armée de terre (malheureusement, pour le moment, nous ne pouvons pas estimer précisément leur nombre).

Au moins 287 officiers de carrière et 120 officiers de réserve et du temps de guerre avaient quitté l'uniforme en février-mai 1918 et étaient restés sur le territoire de la Finlande, refusant de gagner Kronstadt avec les principales forces de la flotte de la Baltique ${ }^{13}$. Certains d'entre eux sont retournés à Petrograd au cours de l'été 1918 et sont entrés au service de la Marine rouge, comme V. V. Selitrennikov (18821938). Au final, environ $10 \%$ des officiers de marine sont restés en Finlande, ce qui est considérable. L'une des motivations de ceux qui quittaient la marine était la fatigue de la guerre (ce que ces officiers ont écrit eux-mêmes), mais aussi la réticence à « servir les bolcheviks » (Назаренко 2020a, 76-121). La raison officielle de leur départ était le décret sur la dissolution de la « vieille » marine le 29 janvier 1918. Or, la dissolution de l'ancienne marine n'a pas été effective et la plupart des marins et des officiers avaient continué à servir. Il reste que ce décret permettait à ceux qui le souhaitaient de quitter la marine.

Après la concentration de la flotte à Petrograd et à Kronstadt, les organisations secrètes de la garde blanche ont commencé à " recruter pour Mourman ", c'està-dire à mettre en œuvre le transfert illégal d'officiers vers la péninsule de Kola et Arkhangelsk afin de préparer un soulèvement antibolchevique. Nous ne pouvons pas estimer le nombre d'officiers de marine recrutés ainsi, mais nous pouvons constater que, pendant la Guerre civile, environ 800 « vieux » officiers de marine ont servi dans les forces blanches de la région du Nord, dont 410 servaient dans la Flottille de l'océan glacial Arctique avant octobre 1917. Par conséquent, les 390 personnes restantes devaient arriver à Arkhangelsk et Mourmansk de l'extérieur. L'analyse des biographies montre que la grande majorité d'entre eux avaient déjà servi dans la flotte de la Baltique. Ce sont donc environ 400 officiers qui avaient quitté la flotte de la Baltique pour servir les blancs dans le Nord. De même, la grande majorité des quelques 200 officiers de marine qui ont servi dans l'armée blanche du Nord-ouest de N. N. Judenič étaient des anciens de la flotte de la Baltique. Même en Sibérie, où on comptait jusqu'à 900 "vieux » officiers dans les forces armées de Kol'čak, 500 s'étaient rendus en Sibérie depuis la Russie soviétique et provenaient principalement de la flotte de la Baltique ${ }^{14}$.

13 Calculé d’après Архив Управления Федеральной службы безопасности по Санкт-Петербургу и Ленинградской области. Д. П-86300, л. 276-308.

14 Quelques-uns provenaient aussi de la flotte de la mer Noire et environ 400 servaient fin 1917 dans les flottilles de Sibérie et de l’Amour.

CONNEXE 7 | 2021 - La Guerre civile après 1917 : les échelles d'un conflit et sa représentation 
Tableau 3. Choix politique de « vieux officiers » de la flotte de la Baltique en 1918-1919 (Офицеры флота 2017)

\begin{tabular}{|l|r|r|}
\hline Ayant servi dans la Marine Baltique à la fin de 1917 & $+/-4650$ & $\mathbf{1 0 0 \%}$ \\
\hline Ayant servi dans la flotte rouge de la Baltique & $+/-1100$ & $23,6 \%$ \\
\hline $\begin{array}{l}\text { Ayant servi dans les flottilles rouges fluviales et dans les } \\
\text { institutions centrales à Moscou }\end{array}$ & & \\
\hline Total ayant servi dans la Marine rouge & $+/-2000$ & $43 \%$ \\
\hline Passés du côté des blancs et ayant combattu dans le Nord & $+/-400$ & $8,6 \%$ \\
\hline $\begin{array}{l}\text { Passés du côté des blancs et ayant combattu dans l'armée du } \\
\text { Nord-ouest }\end{array}$ & $+/-200$ & $4,3 \%$ \\
\hline Passés du côté des blancs et ayant combattu en Sibérie & $+/-500$ & $10,7 \%$ \\
\hline Total ayant servi chez les blancs & $+/-1100$ & $\mathbf{2 3 , 6 \%}$ \\
\hline Dont on ne connaît pas l'activité pendant la Guerre civile & $+/-1150$ & $\mathbf{3 3 , 3 \%}$ \\
\hline
\end{tabular}

On voit que les «vieux » officiers ont progressivement quitté la Marine rouge, choisissant de servir les blancs ou de ne pas participer à la Guerre civile, ce processus s'étendant du début 1918 au printemps 1919. L’analyse par échantillonnage montre également que 35 à $40 \%$ des officiers des armes de carrière ont servi dans l'Armée et la Marine rouges pendant la Guerre civile, soit environ le même nombre que dans les forces blanches. Il reste un quart de l'échantillon qui a évité de servir dans une force armée quelconque ou sur lesquels nous n'avons aucune information (ce qui indique de toute façon qu'ils avaient quitté l'uniforme). En ce qui concerne les officiers de réserve et du temps de guerre, environ $50 \%$ d'entre eux ont probablement servi dans la Marine rouge, beaucoup moins (pas plus de $10 \%$ à notre avis) dans les forces blanches et environ $30 \%$ ont évité de participer à la Guerre civile.

L'analyse de la composition des forces blanches dans le Nord montre que les officiers de carrière, les amiraux et les généraux de la marine (officiers des armes, ingénieurs-mécaniciens et officiers en l'amirauté) ont plus volontiers rejoint les formations blanches. Leur proportion dans le Nord pendant la Guerre civile était environ 1,7 fois supérieure à celle d'octobre 1917. En revanche, les officiers de réserve et du temps de guerre étaient beaucoup moins nombreux dans les forces blanches du Nord que dans la Flottille de l'océan Arctique en octobre 1917 (6 à 7 fois) (Офицеры флота 2017). 


\section{Conclusion}

En 1918, la plupart des officiers de la marine qui se trouvaient à Petrograd sont restés dans la ville, continuant à figurer dans les cadres de la Marine rouge, ce qui leur a donné les moyens de subsister. Une minorité est restée en Finlande à la faveur de la Campagne de Glace ou a quitté Petrograd pour l'étranger. Moins d'officiers encore ont tenté de se rendre à Arkhangelsk, dans le Caucase du Nord ou en Sibérie pour rejoindre les formations blanches. La question du nombre d'officiers officiellement sous commandement soviétique, qui ont été impliqués dans l'un des nombreux complots antibolcheviques à Petrograd en été et en automne 1918, reste ouverte.

Dans chaque cas, le choix politique d'un officier était dicté par une combinaison unique des facteurs que nous avons décrits : les liens sociaux au sein du corps des officiers, leurs convictions mais aussi leurs ambitions politiques, leur incompréhension des objectifs politiques réels des bolcheviks et leur sensibilité tant aux rumeurs sur les contacts de ces derniers avec les Allemands qu'à l'influence du renseignement britannique, sans oublier la réticence à participer activement à une guerre « fratricide».

L'analyse par échantillonnage montre que moins de $5 \%$ des anciens officiers de la marine russe sont entrés au service des nouveaux États - Pologne, Estonie, Lettonie et Finlande (tout en constituant la majorité dans les marines de ces pays). De 35 à $40 \%$ des officiers des armes de carrière ont servi dans la Marine rouge pendant la Guerre civile et à peu près autant que dans les forces blanches. Il n'y aucune information sur le destin d'environ $25 \%$ d'entre eux, ce qui signifie qu'ils ont quitté le service, soit qu'ils aient sciemment évité d'entrer dans une quelconque formation armée, soit encore en raison des circonstances. Les proportions sont assez différentes en ce qui concerne les officiers de réserve et du temps de guerre qui étaient de plus basse extraction sociale. À peu près $50 \%$ d'entre eux ont servi dans la Marine rouge, contre pas plus de $10 \%$ dans les forces blanches; quelques $30 \%$ ont quant à eux évité de participer à la Guerre civile. On voit ainsi qu'un certain déterminisme social jouait, mais moins comme le reflet d'une lutte des classes qui déchirerait le corps des officiers qu'en conséquence de la plus ou moins grande cohésion interne de ses différentes composantes. 


\section{Références bibliographiques}

C.I.N. 2012. Guide du Marin, Édition 2013. Brest : Marine Nationale.

Eesti Sõjamuuseum - Kindral Laidoneri Muuseum. Eesti Ohvitserid 1918-1940 .

Kadry Morskie Rzeczypospolitej. 2011. Tom V : Polska Marynarka Wojenna. Dokumentacja organizacyjna i kadrowa oficerów, podoficerów i marynarzy (1918-1947). Gdynia : Polskie Towarzystwo Nautologiczne.

Melderis, J. 2016. Latviešu virsnieku reğistrs (1915-1945 gadi). Rīga : Latviešu virsnieku apvienība.

Березовский, Н.Ю. 1996. « Военспецы на службе в красном флоте ». Военно-исторический журнал $2: 53-58$.

Волков, С.В. 1993. Трагедия русского офицерства. М. : Воениздат.

Волков, С.В. 2004. Офицеры флота и морского ведомства. Опыт мартиролога. М. : Русский путь.

Ганин, А.В. 2014. Закат Николаевской военной академии, 1914-1922. М. : Книжница.

Ганин, А. В. 2018. Семь «почему » российской Гражданской войны. М. : « Пятый Рим ».

Граф, Г. К. 1997. На « Новике ». Балтийский флот в войну и революиию. Спб. : Гангут.

Зданович, Александр Александрович. 2003. Организационное строительство отечественной военной контрразведки (1914-1920 г2.) : диссертация ... кандидата исторических наук. М. : Институт военной истории Министерства обороны Российской Федерации.

Зданович, Александр Александрович. 2017. « Британская военно-морская разведка в Петрограде в 1918 г. » Вопросы истории 11 : 101-115.

Игнатьев, В.И. 1922. Некоторые факты и итоги четырех лет Гражданской войны (19171921 г.) Ч. 1. (Октябрь 1917 г. - август 1919 г.) Петроград, Вологда, Архангельск. (Личные воспоминания). М. : Гос. Изд-во.

Кавтарадзе, А.Г. 1988. Военные специалисты на службе Республике Советов 1917-1920 ге. М. : Наука.

Каминский, В.В. 2011. Выпускники Николаевской Академии Генерального штаба на службе в Красной Армии. Спб. : Алетейя.

Каминский, В.В. 2013. Ганин А.В. - « творец » « мертвых душ » в Корпусе Генерального Штаба Красной Армии или повесть о том, как не следует заниматься научноисследовательской работой. Уфа : Словохотов А.А.

Ковалев, Э.А. 2006. Короли подплава в море червонныцх валетов. М. : Центрполиграф.

Копелев, Д.Н. 2000. ОФицеры немецкого происхождения на службе в российском флоте, первая половина ХIX в. Дисс. ... канд. истор. наук. Спб. : Санкт-Петербургский государственный университет.

Кузнецов, Н.А. 2009. Русский Флот на чужбине. М. : Вече.

Лобыцын, В.В., ред. 2001. Мартиролог русской военно-морской эмиграции по изданиям 1920-2000 ге. М. : Феодосия. 
Мажара, П.Ю. 2019. « Офицерство Балтийского флота в условиях распада империи и проблема сохранения флота (1917-1921 гг.) » Russian Colonial Studies 3 : 53-71.

Мирский, Г.И. 1976. « Третий мир » : Общество, власть, армия. М. : Наука.

Назаренко, К.Б. 2017. Балтийский флот в революции. 1917-1918 ге. М. : Яуза-ЭксмоЯкорь.

Назаренко, К.Б. 2018. Закат царского флота : Морские офицеры Первой мировой. М. : Яуза-Эксмо-Якорь.

Назаренко, К.Б. 2019. Флот и власть в России : От Цусимы до Гражданской войны. 19051921. М. : Яуза.

Назаренко, К.Б. 2020а. Ледовый поход « адмирала » Щастного : Кораблекрушение в море революции. Спб. : Питер.

Назаренко, К.Б. 2020b. « Последние гардемарины » in Судъба Русской эскадры : корабли и люди : Материалы Международной историко-просветительской конференции (Санкт-Петербург, 21-22 ноября 2019 г.), ред. С. А. Мозговой, 165-174. М. : Институт Наследия.

Никитин, В. 2017. Финская армия : Русский след. Люди и оружие. СПб. : Остров.

Офицеры флота : Просопографическая база данных, 2017. (офицерыфлота.рф).

Павленко, А.П. 2019. « Бывшие офицеры - командующие красными флотилиями на востоке и юго-востоке России в годы Гражданской войны » in Гражданская война на востоке России : взгляд сквозь документальное наследие : материалы III Всерос. науч.практ. конф., посвящ. 100-летию восстановления совет. власти в Сибири (Омск, 1314 нояб. 2019 г.), ред. Д.И. Петин, 174-177. Омск : Изд-во ОмГТУ.

Рабинович, А. 2001. « Досье Щастного : Троцкий и дело героя Балтики ». Отечественная история. 1 : 61-82.

Старцев, В.И. 2001. Ненаписанный роман Фердинанда Оссендовского. Спб. : Скарабей.

Стрельбицкий, К.Б. 2003. « Судьбы офицеров польского ВМФ - выпускников военноморских учебных заведений России в период Второй мировой войны (1939-1945) ». Елагинские чтения 1 : 97-101.

Толочко, А.В. 2012. Русская военно-морская эмиграция : Дисс. ... канд. истор. наук. Пермь : пермский государственный национальный исследовательский университет.

Шошков, Е.Н. 2001. Наморси А. М. Щастный : (Трагическая биография в событиях, датах и комментариях). Спб. : Петровский фонд.

Open Access Publications - Bibliothèque de l'Université de Genève

Creative Commons Licence 4.0

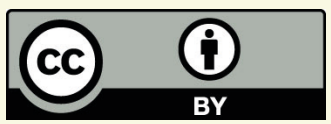

CONNEXE 7 | 2021 - La Guerre civile après 1917 : les échelles d'un conflit et sa représentation 